\title{
IN VITRO WEAR OF 4 DIFFERENT UNIVERSAL COMPOSIES
}

\section{Patricia Matias $^{1 \mathrm{a}}$, Jean-François Roulet ${ }^{2 \mathrm{~b} *}$, Nader Abdulhameed ${ }^{2 c}$, Chiayi Shen ${ }^{2 \mathrm{~d}}$}

${ }^{1}$ University of Brasilia, Department of Dentistry, Brasilia DF 70910-900, Brazil

${ }^{2}$ Department of Restorative Dental Sciences and Center of Dental Biomaterials, College of Dentistry, University of Florida, Gainesville FL32610-0415, USA

aDDS student, Scientific Initiation Scholar

${ }^{b} \mathrm{DDS}$, PhD, Prof hc, Director of Center for Dental Biomaterials

'BDS, MS, Visiting scientist, Candidate PhD Material Sciences

dPhD, Professor

Received: January 27, 2016

Received in revised form: February 14,2016

Accepted: April 22, 2016

Published online: February 10, 2016

Cite this article:

Matias P, Roulet JF, Abdulhameed N, Shen C. In vitro Wear of 4 different Universal Composites. Stoma Edu J. 2016; 3(1-2:39-46.

Objectives: To test the hypotheses: (1) there is no difference in the volumetric wear among composites tested, and (2) there is no difference in the wear rates calculated from the linear relationship of wear increase over cycling.

Methods: Two composites comprising pre-polymerized particles (Herculite-Précis [H], Tetric-N-Ceram $[\mathrm{T}]$ ), one composite with very fine glass fillers (Charisma Opal [C]), and one composite with a mixture of agglomerated and nonagglomerated silica, and zirconia fillers (Filtek Z 350 XT [F]) were tested in a chewing simulator (CS 4.8, SD Mechatronik) with spherical Steatite antagonists $(\varnothing 6 \mathrm{~mm}$ ). Eight specimens of each composite were made by applying two increments in aluminum specimen-holders with a cylindrical cavity $(\varnothing 8 \mathrm{~mm}$, depth $1.5 \mathrm{~mm}$ ), light cured (Bluephase $\mathrm{G} 2 ; 1383 \mathrm{~mW} / \mathrm{cm} 2$ ) for 20 $\mathrm{s}$, polished to high gloss, and subjected to mastication cycles $(59 \mathrm{~N}, 1.2 \mathrm{~Hz}$, lateral movement 0.7 $\mathrm{mm})$ and thermocycles $\left(5 / 55^{\circ} \mathrm{C} ; 116 \mathrm{~s}\right.$ per cycle) simultaneously. After each 100, 500, 1,000, 2,000, $5,000,10,000,20,000,30,000,40,000,50,000,60,000,70,000,80,000,90,000,100,000,110,000$, and 120,000 mastication cycles, 3D images of worn surfaces were captured with Laserscanner LAS-20 (SD Mechatronik), and volumetric wear in $\mathrm{mm} 3$ was calculated by Geomagic software.

Results: Five samples were lost due to separation at interface between increments. The means of total volumetric wear (mean \pm SD) after 120,000 cycles are $0.78 \pm 0.26 \mathrm{~mm} 3,0.91 \pm 0.15 \mathrm{~mm}, 0.99 \pm 0.29 \mathrm{~mm}$, and $1.15 \pm 0.36 \mathrm{~mm} 3$ for $F, H, T$ and $C$. Wear rate of each surviving sample between 2,000 and 120,000 cycles was calculated by linear regression ( $R 2>0.99$ for all specimens). The wear rates (mean $\pm S D ; \mu m 3 /$ cycle) are, $5.97 \pm 2.29 \times 103,6.85 \pm 1.06 \times 103,8.91 \pm 2.81 \times 103$ and $6.43 \pm 0.58 \times 103$ for $F, H, T$ and C. GLM shows statistically significant differences in the wear rate among the four materials $(p=0.0488)$. Looking at the total volumetric wear of the four composites ) and wear of antagonists no differences were found $(p=0.1183(p=0.3027)$ respectively.

Conclusions: The first hypothesis was accepted and the second hypothesis was rejected. To prevent separation between increments, future specimen preparation should consider bulk fill.

Keywords: composite, in vitro wear, chewing simulator.

\section{Introduction}

When composite resins were introduced to the market, depending on the filler content, some of them were recommended for anterior and posterior use. Adaptic (Johnson \& Johnson, New Brunswick NJ, USA) composite material was chosen for a clinical study primarily based on mechanical and physical data. ${ }^{1}$ Furthermore the authors reported wear results obtained with a tooth brushing machine. Adaptic showed similar wear as compared to amalgam, when abraded with a slurry of heavy $\mathrm{CaCO}_{3}$, though $4 x$ less wear when abraded with pumice. This was not clinically confirmed. In a 3-year report, the same authors ${ }^{2}$ using the USPHS criteria for evaluating restorations described a dramatic decrease in the quality of the occlusal anatomy from 44 "Alpha" at baseline to 6 "Alpha" and 36 "Bravo" ratings, which was interpreted as wear. This result was confirmed by Roulet et al. ${ }^{3}$ However, the wear in that study was measured using a 3 coordinate measuring machine. Using a $100 \mu \mathrm{m}$ grid the $\mathrm{x}, \mathrm{y}$, and $\mathrm{z}$ coordinates, wear was determined at approximately 60 points per occlusal surface. The average vertical wear after 3 
Table 1. Products manufacturers, filler composition, and batch numbers

\begin{tabular}{|c|c|c|c|c|}
\hline Code & Name & Manufacturer & Filler & Lot \\
\hline $\mathrm{C}$ & $\begin{array}{l}\text { Charisma Opal. } \\
\text { A2 }\end{array}$ & $\begin{array}{l}\text { Heraeus Kulzer } \\
63540 \text { Hanau } \\
\text { Germany }\end{array}$ & Ba-Al glass, $0.02-2 \mu \mathrm{m}, 20-70 \mathrm{~nm} \mathrm{SiO}_{2}$ & 010025 \\
\hline $\mathrm{F}$ & $\begin{array}{l}\text { Filtek Z350XT } \\
\text { A2 body }\end{array}$ & $\begin{array}{l}\text { 3M ESPE } \\
82229 \text { Seefeld } \\
\text { Germany }\end{array}$ & $\begin{array}{l}\text { Agglomerated/non-aggregated } 20 \mathrm{~nm} \text { silica } \\
\text { filler, non-agglomerated/non-aggregated } \\
4 \text { to } 11 \mathrm{~nm} \text { zirconia filler, and aggregated } \\
\text { zirconia/silica cluster filler (comprised of } 20 \\
\mathrm{~nm} \text { silica and } 4 \text { to } 11 \mathrm{~nm} \text { zirconia particles). }\end{array}$ & N321220 \\
\hline $\mathrm{H}$ & $\begin{array}{l}\text { Herculite } \\
\text { Precis A2 }\end{array}$ & $\begin{array}{l}\text { Kavo Kerr } \\
\text { Charlotte } \\
\text { NC } 28273 \\
\text { USA }\end{array}$ & $\begin{array}{l}\text { Ba glass } 0.4 \mu \mathrm{m}, \mathrm{PPF}, \\
20-50 \mathrm{~nm} \mathrm{SiO}_{2}\end{array}$ & 3649560 \\
\hline $\mathrm{T}$ & $\begin{array}{l}\text { Tetric N-Ceram } \\
\text { A2 }\end{array}$ & $\begin{array}{l}\text { Ivoclar Vivadent } \\
\text { 9494-Schaan } \\
\text { Liechtenstein }\end{array}$ & $\begin{array}{l}\text { Ba-Al glass, } 0.5 \text { and } 0.7 \mu \mathrm{m}, \mathrm{PPF} \text {, mixed } \\
\text { oxide spheres } 160 \mathrm{~nm}, \mathrm{Ytterbium} \\
\text { trifluoride } 180 \mathrm{~nm}, \mathrm{SiO}_{2} 40 \mathrm{~nm}\end{array}$ & P72199 \\
\hline
\end{tabular}

years for Adaptic was $224 \pm 151 \mu \mathrm{m}$. Using better equipment, it became possible to distinguish between wear in the occlusal contact area (OCA) and the contact free area (CFA). It was found that the OCA:CFA ratio equals an average of $2.5 .{ }^{4}$ Different equipment was used to accomplish this: Profilometer, ${ }^{5,6} 3$ coordinated table using a long lens to determine the vertical dimension, ${ }^{7}$ and a computer controlled 3-coordinated table with a mechanical switch for the vertical dimension. ${ }^{8}$ Today, laser scanners measure fast and efficient occlusal anatomy and wear. ${ }^{9}$

Current composite wear resistance has vastly improved mainly due to refinement of filler technology. ${ }^{10}$ Clinical studies document the excellent longevity of posterior composite restorations if applied correctly; ${ }^{11-15}$ therefore, it seems that wear is no longer the primary concern. Wear behavior of restorative materials will remain important and in focus, since today more and more occlusal bearing restorations are placed clinically due to the recent expansion of the indication for composites, including cusp replacements. Palaniappan et al. ${ }^{16}$ reported that hybrid composites had a vertical substance loss within the same magnitude as enamel. However, comparing the volumetric wear, enamel was worn significantly less than the 3 tested composites. Frankenberger et al. ${ }^{17}$ observed significant wear of nanohybrid and fine hybrid composite restorations in extended class II cavities after 8 years of service. With more nanoparticle-based composite materials being introduced, there is a need of investigating wear resistance of those materials. Therefore, the objective of this investigation was to measure in vitro wear of 4 nano particle based, commercial universal composites.

The null hypotheses are (1) there is no difference in volumetric wear among composites tested, and (2) there is no difference in wear rates calculated from the linear relationship of wear increase over cycling.

\section{Materials and Methods}

The four universal composites were received and the samples prepared according to standard procedures being equal for each brand. The manufacturer, filler composition and lot numbers are displayed in Table 1. Eight samples were prepared for each brand $(n=8)$, which resulted in total 32 samples.

Thirty-two aluminum sample holders (inner $\varnothing$ $7.9 \mathrm{~mm}$ depth $1.5 \mathrm{~mm}$ ) were grit blasted with $27 \mu \mathrm{m}$ aluminum oxide (EtchMaster Tips Small, Groman, USA) then one coat of universal bond (Monobond Plus, Ivoclar Vivadent, Liechtenstein) was added and left for 60 seconds, followed by air blasting to evaporate the solvent. Then one coat of adhesive (Optibond FL 2, Kerr, USA) was applied and light cured for $10 \mathrm{~s}$ using the BluephaseG2 (Ivoclar Vivadent, Liechtenstein) at "HIGH Power" mode delivering $1383 \mathrm{~mW} / \mathrm{cm}^{2}$ at a distance of $1.5 \mathrm{~mm}$ (verified with MARC Resin calibrator, BlueLight Analytics Inc., Halifax, NS, USA). The composites were filled into the sample holders in two increments, and each was light cured for a total of $40 \mathrm{~s}$ that delivered $55 \mathrm{~J} / \mathrm{cm}^{2}\left(1383 \mathrm{~mW} / \mathrm{cm}^{2} \times 40\right)$. The composite surfaces were finished and polished by using (Sof-Lex Discs, 3M, USA), light orange disc for finishing and yellow disc for polishing for 10 $15 \mathrm{~s}$. All samples were stored in distilled water for 3 weeks at $37^{\circ} \mathrm{C}$. Steatite balls $(\varnothing 6 \mathrm{~mm}$ ) mounted into aluminum holders with composite were used as antagonists. One antagonist per sample $(n=32)$ was used and discarded after finishing all cycles. The samples were randomly distributed to the chewing simulator chambers (CS-4, Mechatronik, Germany) using random numbers. The chewing simulator was run according to the parameters listed in Table 2. The composite samples were scanned after 100,500, 1,000, 2,000, 5,000, 10,000, 20,000, 30,000,40,000,50,000, 60,000, $70,000,80,000,90,000,100,000,110,000$, and 120,000 mastication cycles. 


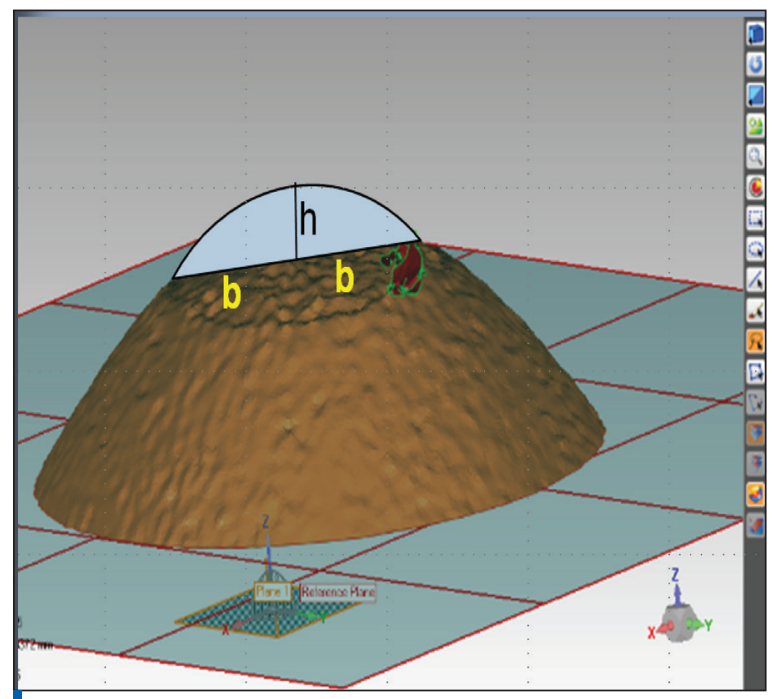

Figure 1a. Wear facets were mostly symmetrical and round. By tracing the perimeter in the Keyence Microscope, the radius of the circle determining the "wear dome" could be determined

By using geometric software (Geomagic Control 2014, Geomagic, Cary, NC, USA), the scanned data was used to measure the wear of the samples after each round.

The flat surface of the sample was used as a reference plain. All wear facets at 120,000 cycles were examined with a digital microscope and digital images recorded (Keyence VHX 1000, Keyence Corporation of America, Elmwood Park, NJ, USA).

The wear of the Steatite antagonists was not measured with the laser scanner due to difficulty of establishing reference plane. They were determined indirectly by the geometric relationship (Fig. 1a). The radius (b) of the wear facet was measured using the Keyence digital microscope. Knowing the radius ( $r$ ) of the sphere, we calculated the height of the abraded dome $(h)$ using the following formula (Fig $1 \mathrm{~b}$ ),

$$
h=r-\sqrt{\left(r^{2}-b^{2}\right)}
$$

The volume of the wear dome $(\mathrm{V})$ was calculated using the following spherical cap formula from standard mathematical tables,

$$
V=1 / 3 \pi h^{2}(3 r-h)
$$

Samples C1, C3, C4, F2 and F7, experienced delamination at the interface between increments before conclusion of the experiment. Therefore they were excluded from the analyses. Due to imbalanced numbers of specimen per group of composites, GLM (SAS, 9.4; SAS Institute Inc., Cary, NC, USA) was used to analyze the variance of wear volume of the composites and antagonists. After the initial wear-in period, linear relationship between the wear volume and number of cycles from 2,000 to 120,000 cycles was apparent for all samples investigated. Linear regression was performed using SAS to determine the slope

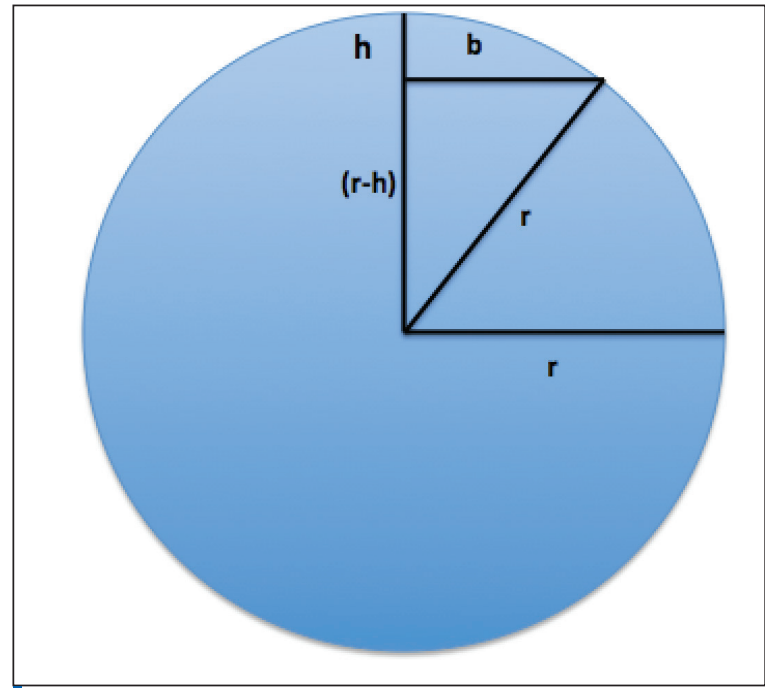

Figure $\mathbf{1 b}$. With the known radius ( $r$ ) of the sphere and the radius of the wear facet (b), the volume of the "wear dome can be calculated

of the curve. The values represent the wear in $\mu^{3}{ }^{3}$ cycle of the samples and were called wear rate in this paper. GLM was used to determine statistical differences of wear rates among the four composite groups. The correlation coefficients $\left(r^{2}\right)$ between wear of antagonists and volumetric wear of composites, and between wear of antagonist and wear rate of composites were calculated by linear regressions.

\section{Results}

GLM analyses showed that after 120,000 chewing cycles there were no statistical differences in total volumetric wear among the four composites $(p=0.1183)$ and wear of antagonist $(p=0.3027)$ with its respective composite. Linear regressions of the composite wear volume vs. number of cycles showed that the degree of fit $\left(r^{2}\right)$ was $>0.99$ for each of the specimen investigated. GLM analysis of the values of wear rate determined for each specimen shows there was statistically significant difference among composites groups $(p=0.0488)$. It is important to note that the $p$-value was almost at the point of no significant difference $(p=0.05)$. The mean values and standard deviation of the total wear volume at 120,000 chewing cycle, wear of respective antagonist and the wear rates are shown in Table 3. The mean cumulative wear volumes as a function of the number of cycles, along with the best fit straight line of the mean values for each group of composite are displayed in Fig. 2. Analysis of the correlation showed that both wear volume and wear rate increased slightly as the wear of antagonist increased but with low correlation coefficient $\left(r^{2}=0.0027\right.$ and $r^{2}=0.2081$, respectively).

Some illustrative pictures of wear facets of the composites are shown in Fig. 3. 
Table 2. Settings of Chewing Simulator

\begin{tabular}{|c|c|}
\hline Load & $6 \mathrm{Kg}$ \\
\hline Upstroke & $2 \mathrm{~mm}$ \\
\hline Downstroke & $1 \mathrm{~mm}$ \\
\hline Horizontal movement & $0.7 \mathrm{~mm}$ \\
\hline Upward speed & $60 \mathrm{~mm} / \mathrm{s}$ \\
\hline Downward speed & $60 \mathrm{~mm} / \mathrm{s}$ \\
\hline Horizontal speed & $40 \mathrm{~mm} / \mathrm{s}$ \\
\hline Frequency & $1.2 \mathrm{HZ}$ \\
\hline Thermocycling & $\begin{array}{c}5^{\circ} \mathrm{C}-55^{\circ} \mathrm{C} ; 116 \text { s/cycle; } \\
\text { total } 860 \text { cycles }\end{array}$ \\
\hline Direction & Back and Forth \\
\hline
\end{tabular}

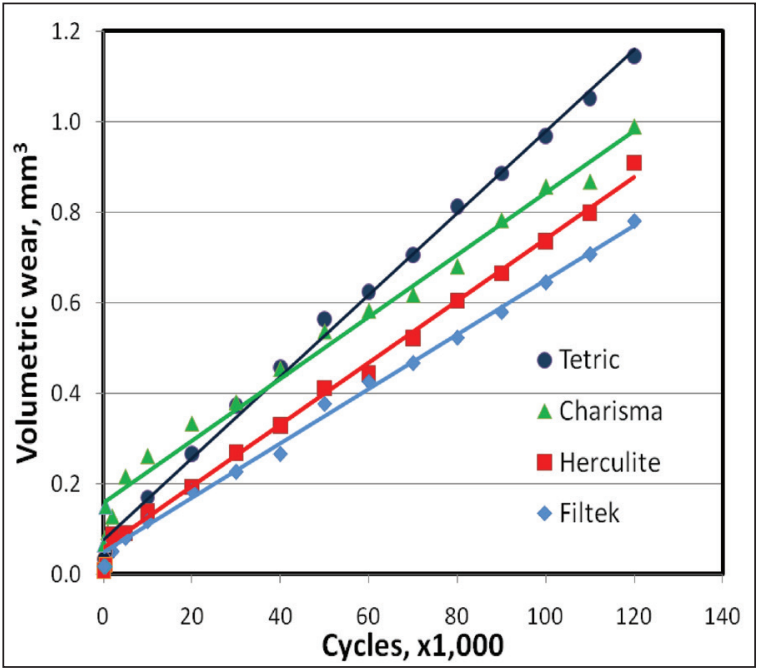

Figure 2. Mean wear of the four groups of composites up to 120,000 cycles. The respect straight for each material group represents the results of linear regression of wear between 2,000 and 120,000 cycles $\left(R^{2}>0.99\right)$.

Table 3. Wear of composite and respective Steatie antagonists at $120 \mathrm{~K}$ cycles

\begin{tabular}{|c|c|c|c|c|c|c|}
\hline \multirow{2}{*}{ Materials } & \multicolumn{2}{|c|}{ Wear of composite, $\mathrm{mm}^{3}$} & \multicolumn{2}{|c|}{$\begin{array}{c}\text { Wear of Steatie antagonist, } \\
\mathrm{mm}^{3}\end{array}$} & \multicolumn{2}{|c|}{$\begin{array}{c}\text { Composite wear rate, } \\
\mu \mathrm{m}^{3} / \mathrm{cycle}\end{array}$} \\
\cline { 2 - 7 } & Mean & SD & Mean & SD & Mean & SD \\
\hline Filtek Z350XT & 0.78 & 0.26 & 0.46 & 0.30 & $5.97 \times 10^{3}$ & $2.29 \times 10^{3}$ \\
\hline Herculite Precis & 0.91 & 0.15 & 0.52 & 0.13 & $6.85 \times 10^{3}$ & $1.06 \times 10^{3}$ \\
\hline Charisma & 0.99 & 0.29 & 0.32 & 0.23 & $6.43 \times 10^{3}$ & $0.58 \times 10^{3}$ \\
\hline Tetric N-Ceram & 1.15 & 0.36 & 0.51 & 0.23 & $8.91 \times 10^{3}$ & $2.81 \times 10^{3}$ \\
\hline
\end{tabular}

\section{Discussion}

The wear of all composites investigated were in a linear relationship with respect to the number of chewing cycles after wear-in period and thestatistical analyses showed that there is significant difference among the composites in wear rate at $p=0.0448$ and no significant difference $(p=0.1183)$ in final volumetric wear. Therefore, the first hypothesis was accepted and the second hypothesis was rejected. Various wear testers have been used to investigate the wear behavior of composites since their introduction. Wear simulation is a very complex process and over the last 40 years scientists have tried to build devices capable of simulating the wear of dental restorative materials. The outcome is heavily influenced by a multitude of factors, such as wear type reflected by the wear testing equipment, the load used, the antagonist material and shape, the use of thermocycling and finally of the material that is worn. One family of wear devices uses 3-body wear. This means that a third body, mimicking food, is forced between the two bodies which stress the material with wear.

Such devices are the ACTA wear machine, ${ }^{18}$ the Oregon Health Science University (OHSU) machine, ${ }^{19}$ the Alabama wear simulator, ${ }^{20}$ and the CW3 of Peking University ${ }^{21}$ and multiple toothbrushing machines. ${ }^{22,23}$ Common to these devices is the introduction of a third body in suspension that affects the results heavily and it is not known which quality of the third body would be clinically relevant for wear of the occlusal surface. The ACTA machine can be run as a two body wear tester as well, having the two wheels run in contact. Osiewicz et al. ${ }^{24}$ have reported differences in wear between 1 and 62.5 fold more wear for moving from 2-body wear to 3-body wear using the same abrasive, but different material combinations (4 composites for antagonist wheel and 6 composites for other wheel).

Another approach is to use a two body wear. A simple and widely used device is the Taber abraser, ${ }^{25}$ which comprises two abrasive wheels engaging on a rotating disk under constant pressure. Two body wear can be induced as a pin on block principle where a pin (antagonist) is 


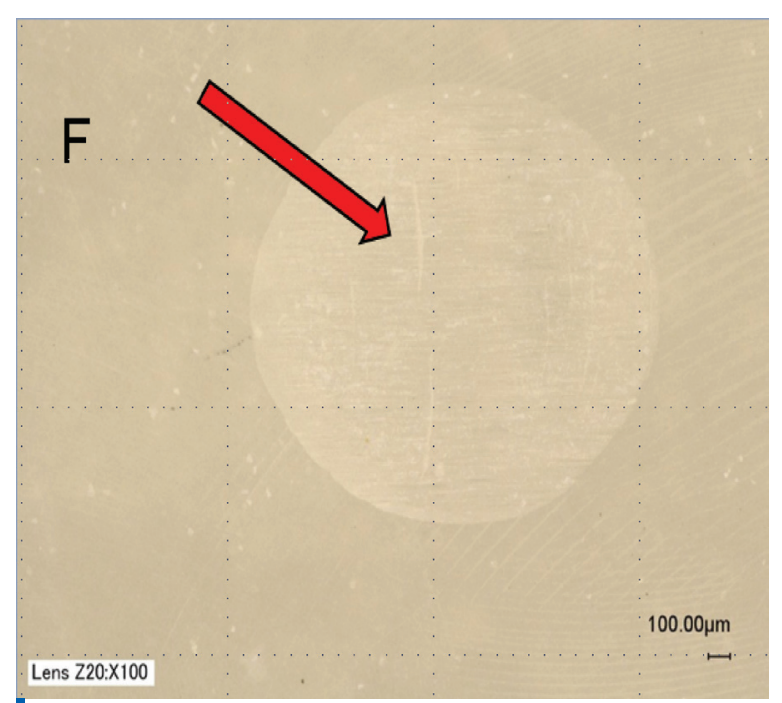

Figure 3a. Wear facette of Filtek Z 350 after 120.000 cycles. Note the white line perpendicular to the direction of the wear

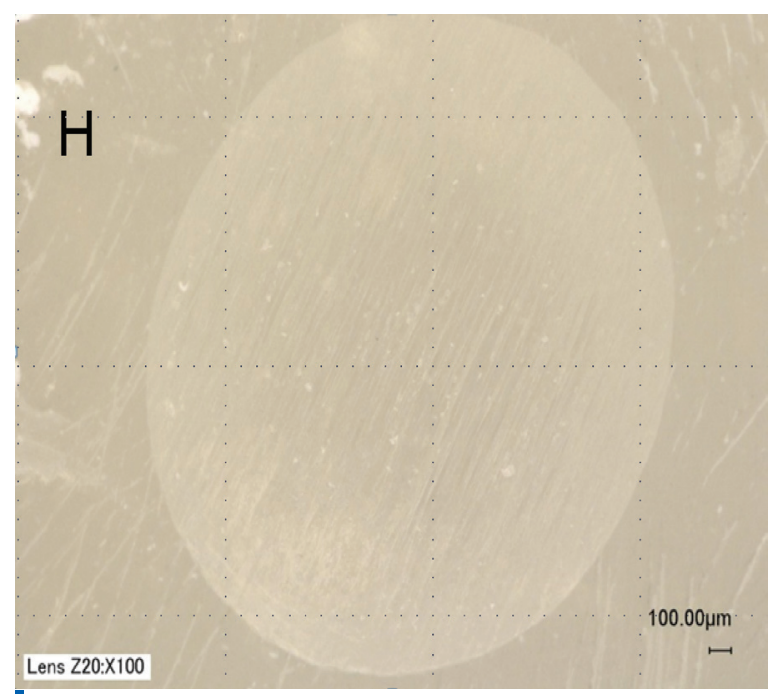

Figure 3c. Wear facet of Herculite Precis after 120,000 cycles

pressed under constant force onto a rotating disk ${ }^{26}$ or oscillated against a flat surface. ${ }^{27}$ Using a pin on block approach, scientists have tried to simulate chewing movements by having an antagonist lowered on a surface, then slid sideways under load, disengaged from the load and being moved to starting point to begin the next cycle. ${ }^{28}$

Such devices are the Willitec Chewing simulator, ${ }^{29}$ the Minnesota artificial mouth, ${ }^{30}$ the CoCom Chewing simulator, ${ }^{31}$ the TE88, ${ }^{32}$ the Tokyo Medical Dental University Chewing simulator ${ }^{33}$ or the Mechatronik Chewing simulator used in the present study. We decided to use a Pin on block chewing simulator, because the load and movements are well controlled and there is no third body to deal with, which makes interpretation of the results less problematic.

Chewing forces are reported in the literature to vary from $20-120 \mathrm{~N} .{ }^{34}$ Most researchers use $5 \mathrm{Kg}$ (49N),

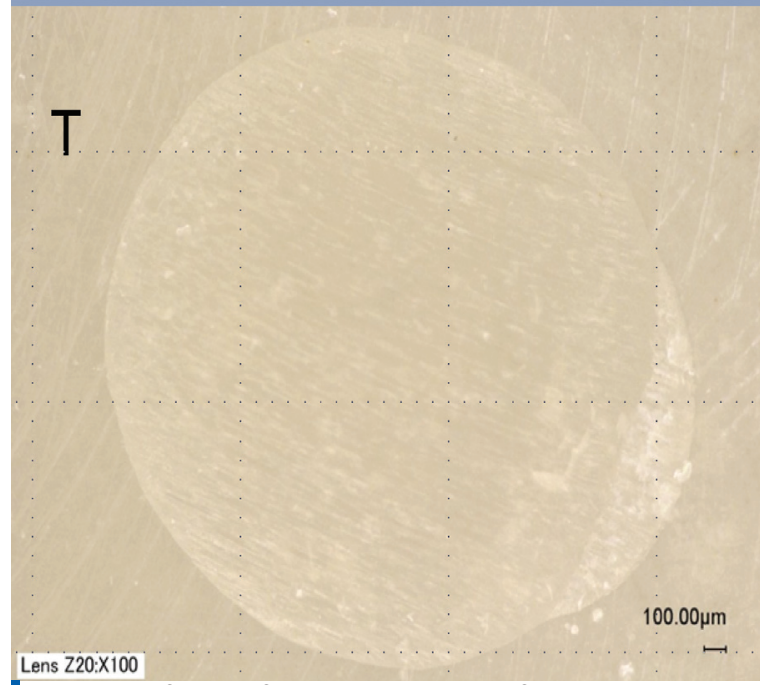

3b. Wear facet of Tetric N-Ceram after 120,000 cycles

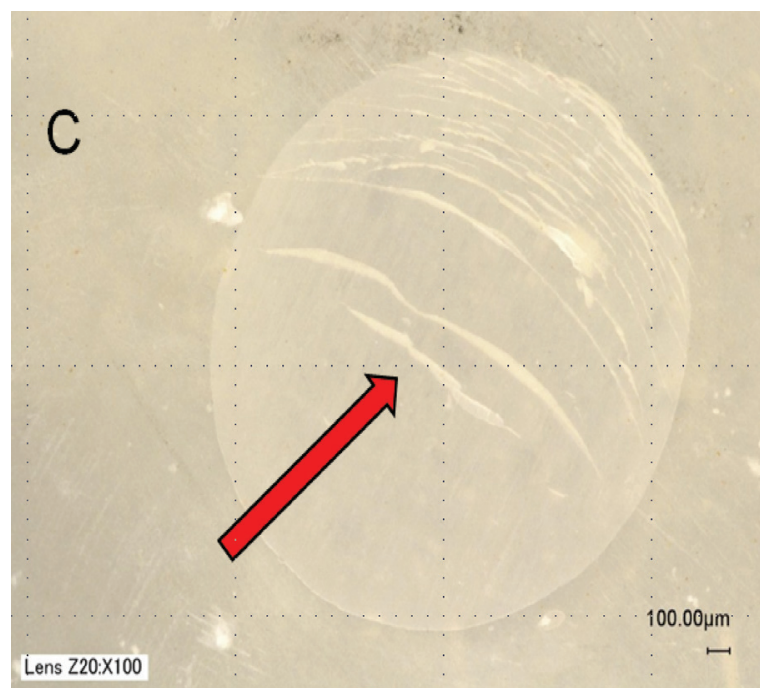

Figure 3d. Wear facet of Charisma Opal after 120,000 cycles. Note the multiple white lines perpendicular to the direction of the wear scratches

which has been reported by Gibbs et al. ${ }^{35}$ to be the average chewing force under normal function. For the present study, $6 \mathrm{~kg}(58.9 \mathrm{~N})$ was chosen, with the idea to be able to better discriminate between the materials having a slightly higher load. However, the higher load apparently was incapable of discriminating the wear rate among the four material groups. Therefore, $5 \mathrm{~kg}$ load should be adopted as a standard for future study for ease of comparison. All wear facets exhibited typical grooves resulting from abrasive wear by harder antagonists with unique feature for each material. For Charisma (Fig. 3d), the white lines common for that group of material are not cracks on the surface but wear debris being folded perpendicular to the direction of horizontal movement. Some worn surfaces of Tetric-N-Ceram samples appear to have a round tab to the oval wear spot (Fig. 3b). The likely cause is that samples had shifted in the 
initial stage of testing.

There is no agreement in the literature about the material and the shape of the antagonists to be used in in vitro wear studies. The following materials have been reported ${ }^{34}$ : stainless steel, natural teeth, tooth cusps shaped to a specific shape and highly polished, leucite reinforced ceramic (Empress), Steatite (magnesium silicate ceramic), Degusit (aluminum oxide) and Zirconium oxide. ${ }^{36}$ Average radius of natural cusps is 1.04 and $1.79 \mathrm{~mm}^{34}$ Artificial materials are used with diameters of $3 \mathrm{~mm},{ }^{36}$ $4 \mathrm{~mm}^{20,33} 6 \mathrm{~mm}^{37,38}$ or $12 \mathrm{~mm} \cdot .^{27,32}$ In the present study $6 \mathrm{~mm}$ Steatite antagonists were chosen. For horizontal movement, both 0.3 and $0.7 \mathrm{~mm}$ have been used, we used $0.7 \mathrm{~mm}$ as it is more commonly used. As a measurement tool a laser scanner was used. Heintze et al. ${ }^{39}$ have shown that laser scanners give the same results as the ones obtained with optical or mechanical profilometers.

Due to the notable differences in in vitro wear testing methods described above it is almost impossible to directly compare the present results to other studies. Therefore, comparisons only to studies done with Willitec/Mechatronik wear testing machines are reported. As in the studies of Heintze et al. ${ }^{34,39}$ and Wang et al. ${ }^{27}$ the wear development over the number of cycles was linear. We can confirm Heintze's data ${ }^{34,39}$ that the Antagonist wear is about half the wear of the composite materials. In contrast, the wear reported for a multitude of materials by Ivoclar Vivadent R\&D is slightly lower than the wear found in this study. This may be due to the higher load used in the present study and the use of different antagonists (Empress vs Steatite). Lazaridou ${ }^{38}$ found for Tetric Evoceram $0.3297 \mathrm{~mm}^{3}$, while Tetric N Ceram in the present study showed $1.15 \mathrm{~mm}^{3}$, which is substantially higher. Again, there are differences in the method which may explain the different findings. The load used in the present study was $20 \%$ higher, and we used thermoclycling in contrast to Lazaridou et al. ${ }^{38}$

Most in vitro wear test methods demonstrate a steep increase in wear initially, also called wear-in or run-in phase, and then a flattening of the curve that appears increasing in a linear fashion, thereafter. The wear profile of individual sample tested and the profile of mean of the material groups all exhibited the wear-in pattern (Fig. 2). The duration of wearin varies among material groups. In the literature, this linear relationship is often recognized $27,34,39,40$ but not used for calculating wear rates. Often for comparison, the final volumes of wear were used for comparison. Since the total volume of wear also depends on the number of cycles and the extent of vertical movement, it becomes necessary have both information available for comparison. Wear-in phase does not truly reflect the wear of the material but include the wear generated during the initial stage when the composite and the antagonist are adjusting to accommodate each other in forming a sliding interface. The linear portion of the curve can be used to calculate the wear rate without the influence of the wearin phase. When the load and the horizontal movement remains the same, the effect of testing duration by cycles disappears when wear rates are used. A straightforward comparison of in vitro wear will become possible. Lastly, the unit for the wear rate should also be standardized. The unit of $\mathrm{mm}^{3}$ is commonly used in discussing of volumetric wear and $\mu \mathrm{m}$ is used in presenting wear in depth. We used the unit $\mu \mathrm{m}^{3} /$ cycle for wear rate in this study. However, the quantity of $\mu \mathrm{m}^{3} /$ cycle is very small, a factor of $10^{3}$ is needed (Table 3). The unit of $\mathrm{mm}^{3}$ / cycle, on the other hand is so big that a factor of $10^{-6}$ is needed. As a compromise, we suggest that $\mathrm{mm}^{3} / \mathrm{megacycle}$ be used in expressing volumetric wear for comparison. As such the values of wear rates shown in Table 3 would be presented without the factor of $10^{3}$.

\section{Conclusions}

The four tested composites showed a linear development of wear over the number of cycles and showed a wear which was comparable to wear in other studies.

It can be expected that in the clinical reality they will behave similarly to other composites of their class.

\section{Acknowledgments}

The authors declare no conflict of interest related to this study. There are no conflicts of interest and no financial interests to be disclosed.

\section{REFERENCES}

1. Phillips RW, Avery DR, Mehra R, Swartz ML, McCune RJ. Oneyear observations on a composite resin for Class II restorations. J Prosthet Dent. 1971;26(1):68-77.

2. Phillips RW, Avery DR, Mehra R, Swartz ML, McCune RJ. Observations on a composite resin for Class II restorations: three year report. J Prosthet Dent. 1973;30(6):891-897.

3. Roulet JF, Mettler P, Friedrich U. [The abrasion of composites in the region of the lateral teeth--results after 3 years].Dtsch Zahnarztl Z. 1980;35(4):493-497.

4. Lutz F, Phillips RW, Roulet JF, Setcos JC. In vivo and in vitro Wear of Potential Posterior Composites. J Dent Res. 1984;63(6):914-920.
5. Lutz F, Imfeld T, Meier CH, Firestone AR. Composites vs Amalgam - Comparative Measurements of in vivo Wear resistance; 1 year report. Quintessence Internat. 1979;14(1):77-87.

6. Lutz F. Beiträge zur Entwicklung von Seitenzahnkomposits. PhD thesis. Zürich: Verlag KAR PAR PZM; 1980.

7. Lambrechts P, Vanherle G, Vuylsteke M, Davidson CL. Quantitative Evaluation of the wear resistance of posterior dental restorations: a new three-dimensional measuring technique. J Dent. 1984;12(3):252-267.

8. Roulet J-F. Degradation of Dental Polymers. Basel, Switzerland: S. Karger AG; 1987. 
9. DeLong R. Intra-oral restorative materials wear: rethinking the current approaches: how to measure wear. Dent Mater. 2006 Aug;22(8):702-711.

10. Ferracane JL. Resin composite - State of the art. Dent Mater. 2011;27(1):29-38.

11. Da Rosa Rodolpho PA, Donassollo TA, Cenci MS, Loguércio AD, Moraes RR, Bronkhorst EM, Opdam NJ, Demarco FF. 22-Year clinical evaluation of the performance of two posterior composites with different filler characteristics. Dent Mater. 2011;27(10):955-963.

12. Krämer N, Reinelt C, Frankenberger R. Ten year clinical performance of posterior resin composite restorations. J Adhes Dent. 2015;17(5):433-441.

13. Lempel E, TóA, Fábián T, Krajczár K, Szalama J. Retrospective evaluation of posterior direct restorations: 10 year findings. Dent Mater. 2015;31(2):115-122.

14. van Dijken JW, Pallesen U. A randomized 10-year prospective follow-up of Class II nanohybrid and conventional hybrid resin composite restorations. J Adhes Dent. 2014;16(6):585592.

15. Pallesen U, van Dijken JWV. A randomized controlled 30 years follow up of three conventional resin composites in Class II restorations. Dent Mater. 2015;31(10):1232-1244.

16. Planiappan S, Elsen L, Lijnen I, Peumans M, Van Meerbeek $B$, Lambrechts P. Three-year randomized clinical trial to evaluate the clinical performance, quantitative and qualitative wear patterns of hybrid composite restorations. Clin Oral Investig. 2010;14(4):441-458.

17. Frankenberger R, Reinelt C, Krämer N. Nanohybrif vs. fine hybrid composite in extended class II cavities: 8-year results. Clin Oral Investig. 2014;18(1):125-37.

18. De Gee AJ, Pallav P, Davidson CL. Effect of abrasion medium on wear of stress bearing composites and amalgam in vitro. J Dent Res. 1986;65(5):654-658.

19. Condon JR, Ferracane JL. Evaluation of composite wear with a new multi-mode oral wear simulator. Dent Mater. $1996 ; 12(4): 218-226$.

20. Leinfelder KF, Beaudreau RW, Mazer RB. An in vitro device for predicting clinical wear. Quintessence Int. 1989;20(10):755761.

21. Han JM, Zhang H, Choe HS, Lin H, Zheng G, Hong G. Abrasive wear and surface roughness of contemporary dental composite resin. Dent Mater J. 2014;33(6):725-732.

22. Al Khuraif AA. An in vitro evaluation of wear and surface roughness of particulate filler composite resin after tooth brushing. Acta Odontol Scand. 2014;72(8):977-983.

23. Aker JR. New composite resins: comparison of their resistance to tooth brush abrasion and characteristics of abraded surfaces. J Am Dent Assoc. 1982;105(4):633-635.

24. Osiewicz MA, Werner A, Pytko-Polonczyk, Roeters FJM, Kleverlaan CJ. Contact and contact free wear between various resin composites. Dent Mater. 2015;31(2):134-140.
25. Winkler MM, Greener EH, Lautenschlager EP. Non-linear in vitro wear of posterior composites with time. Dent Mater. $1991 ; 7(4): 258-262$.

26. Sripetchdanond J, Leevailoj C. Wear of human enamel opposing monolithic zirconia, glass ceramic, and composite resin: an in vitro study. J Prosthet Dent. 2014;112(5):1141-1150. 27. Wang R, Bao S, Liu F, Jiang X, Zhang 0 , Sun B, Zhu M. Wear behavior of light-cured resin composites with bimodal silica nanostructures as fillers. Mater Sci Eng C Mater Biol Appl. 2013;33(8):4759-4766.

28. Kai M, Satou J, Satou N, Shintani H, Fujioka M. Sliding wear of various composite resins and bovine enamel. Dent Mater J. 1986;5(2):165-171.

29. Kunzelmann KH. Verschleissanalyse und -quantifizierung von Füllungsmaterialien in vivo und in vitro. Aachen: Shaker Verlag; 1998.

30. DeLong R, Douglas WH. Development of an artificial oral environment for the testing of dental restoratives: bi-axial force movement control. J Dent Res. 1983;62(1):32-36.

31. Krejci I, Reich T, Lutz F Albertoni M. [An in vitro test procedure for evaluating dental restoration systems. 1. A computercontrolled mastication simulator]. Schweiz Monatsschr Zahnmed. 1990;100(8):953-960.

32. Hao Z, Yin H, Wang L, Meng Y. Wear behavior of seven Artificial resin teeth assessed with three-dimensional measurements. J Prosthet Dent. 2014;112(6):1507-1512.

33. Koottathhape N, Takahashi H, Iwaqsaki N, Kanehira M, Finger WJ. Quantitative wear and wear damage analysis of composite resin in vitro. J Mech Behav Biomed Mater. 2014;29:508-516.

34. Heintze SD. How to qualify and validate wear simulation devices and methods. Dent Mater. 2006;22(8):712-734.

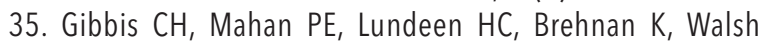
EK, Holbrook WB. Occlusal forces during chewing and swallowing as measured by sound transmission. J Prosthet Dent. 1981;46(4):443-449.

36. D'Arcangelo C, Vanini L, Rondoni GD, Pirani M, Vadini M, Gattone M, De Angelis F. Wear properties of a novel resin composite compared to human enamel and other restorative materials. Oper Dent. 2014;39(6):612-618.

37. Mehl C, Scheibner S, Ludwig K, Kern M. Wear of composite resin veneering materials and enamel in a chewing simulator. Dent Mater. 2007;23(11):1382-1389.

38. Lazaridou D, Belli R, Petschelt A, Lohbauer U. Are resin composites suitable replacements for amalgam? A study of two body wear. Clin Oral Investig. 2015;19(6):1485-1492.

39. Heintze SD, Cavalleri A, Forjanic M, Zellweger G, Rousson V. A comparison of three different methods for the quantification of the in vitro wear of dental materials. Dent Mater. 2006;22(11):1051-1062.

40. Zantner C, Kielbassa AM, Martus P, Kunzelmann KH. Sliding wear of 19 commercially available composites and compomers. Dent Mater. 2004;20(3):277-285. 


\section{Patricia MATIAS}

DDS student, Scientific Initiation Scholar Department of Dentistry, Faculty of Health Sciences, University of Brasília, Brasília, Brazil

Patricia Matias is a DDS student of the University of Brasília (UnB). She had a scholarship for PET-Saúde Extension Program (2010/2012). Since 2010, she has been participating in the Integral Health and Education Extension Project. She also had a scholarship (2013/2014) from CAPES/IIE/Science without Borders to study at the University of Florida (UF). During this period, she studied English, participated in research activities and took courses at the Division of Operative Dentistry and Dental Biomaterials at UF. Therefore, she has benefited from training in dental technology, CAD/CAM, microtensile, thermocycling, chewing simulation, MARC resin calibration (analysis of fotopolimerization light), ceramic and composites. In 2015 she treated children and adults at J.J Mesquita Hospital Ship in Amazonas River-Brazil. Currently, she is a Scientific Initiation Scholar (PIBIC) mentored by Prof Dr. Leandro Augusto Hilgert at UnB and has a scholarship from CNPQ. Her interest lies with Dental Materials and Operative Dentistry.

\section{Ouestions}

\section{In the literature the chewing forces are reported to vary from:}

a. 30 to $50 \mathrm{~N}$;

b. 100 to $800 \mathrm{~N}$;

c. 20 to $120 \mathrm{~N}$;

d. 5 to $25 \mathrm{~N}$.

\section{All the following devices are two body wear devices, with one exception:}

a. TE88;

b. Willitec Chewing simulator;

c. CoCom Chewing simulator;

$\square$ d. Alabama wear simulator.

\section{In in vitro wear studies, one of the following materials is used to create the antagonists:}

$\square$ a. Leucite reinforced ceramic;

b. Dental amalgam;

c. Composite resins;

$\square$ d. Acrylic resin.

\section{We can appreciate that the wear-in phase:}

$\square$ a. Does not include the wear generated during the initial stage;

$\square$ b. Does not truly reflect the wear of the material;

$\square$ c. Appears as a flattening of the wear curve;

$\square \mathrm{d}$. Has the same duration for all tested materials. 